\title{
EL CRISTO DIBUJADO POR SAN JUAN DE LA CRUZ
}

\author{
VICENTE VIÑAS TORNER \\ Jefe del Servicio de Libros y Documentos del \\ Instituto de Conservación y Restauración de Bienes \\ Culturales \\ Madrid
}

Si la obra y figura de San Juan de la Cruz son universalmente conocidas por la poesía de sus escritos y la mística de su doctrina, tan justamente valorada por la Iglesia al otorgar al Santo, en 1926, el título de Doctor en Teología Mística, existe otra faceta en este humilde y glorioso castellano que no por menos fecunda deja de ser meritoria. Se trata de su habilidad artística, tan certeramente comentada, entre otros, por J. Sánchez Cantón quien reconoce la dificultad de hablar del arte de San Juan sin apenas conocer su obra (1).

Aparte de algunas imágenes de Cristo talladas en madera y de la escultura de una Virgen, todas de ignorado paradero, los textos del siglo XVII dan testimonio de dos dibujos autógrafos. El que hace referencia a la difícil subida al Monte Carmelo se ha perdido y sólo resta la vaga idea de un original cubierto de letreros reproducido en un grabado de escasa calidad (2). El segundo es el dibujo a pluma de Cristo muerto en la Cruz, conservado en el Convento de la Encarnación de Avila. Sólo por esta pequeña muestra podemos juzgar lo que pudieron ser las manifestaciones artísticas creadas por la mano y el espíritu del Místico Doctor.

Aunque se ha escrito mucho sobre las circunstancias que motivaron el tema, la rareza e innovación de la iconografía, historia del dibujo... quiero enriquecer los estudios con algunas observaciones personales, uniéndome así al merecido homenaje a D. Gratiniano Nieto, quien ostentaba el cargo de Director del Instituto Central de Conservación y Restauración de Obras de Arte, cuando me cupo la fortuna, en 1969, de restaurar y dar nuevo montaje a tan singular obra, pues a pesar de los desvelos de las Madres Carmelitas el dibujo no podía ser impune a las huellas y avatares marcados por el tiempo.

A finales de 1968 el Padre Juan Bosco (Carmelita Descalzo), alarmado por el deterioro, recurrió a la Dirección General de Bellas Artes y el trabajo fue encomendado, dentro del I.C.C.R., al Departamento de Grabados y Dibujos que yo di-

(1) Sánchez Cantón, F. J.: «San Juan de la Cruz: Si cabe hablar de su arte» en Conmemoración del IV Centenario de San Juan de la Cruz. Publicaciones del Instituto de España, Madrid, 1942, págs. 31-43.

(2) Reproducido en la obra de Fray Silverio de Santa Teresa, Obras de San Juan de la Cruz, Burgos, 1931. 
rigía en aquellos años, recayendo en mi persona la responsabilidad de recuperar tan importante documento.

El soporte material - papel-y la técnica - dibujo a tinta- no diferían, en principio, de los problemas que habitualmente presentan otros dibujos de características similares. Sin embargo, la problemática resultó ser más compleja y merecedora, por el triple valor de la obra - histórico, artístico y espiritual - de toda la dedicación que se le prodigara. En la medida posible me sensibilicé con estos valores (3), esforzándome por averiguar las circunstancias acaecidas hasta alcanzar el estado en que llegaba a mis manos. Aparte, como es lógico, apliqué a su conservación y restauración cuantos medios estaban a mi alcance.

Aunque mi participación se centró en la anulación de los daños y dotar a la pieza de condiciones idóneas para su conservación, el exàmen directo, sin obstáculo alguno, y los análisis realizados revelaron detalles hasta entonces inadvertidos. Para valorar estas aportaciones es preciso recordar la historia de la obra ya que, como se verá más adelante, estamos lejos de precisar cómo fue originariamente el auténtico dibujo de San Juan de la Cruz.

\section{Noticia histórica}

El 6 de octubre de 1571 Santa Teresa tomó posesión como Priora del Convento de la Encarnación y conforme a sus deseos fue nombrado confesor del Monasterio el Padre Juan de la Cruz, nombre con el que se conoce en religión, tras la reforma de la Orden, a Juan de Yepes y Alvarez, quien permaneció en Avila desde 1572 hasta diciembre de 1577. Durante este tiempo realizó el dibujo de Cristo muerto en la Cruz. Sobre las circunstancias que inspiraron el tema y las personas que lo poseyeron tenemos abundantes testimonios recogidos por contemporáneos, hagiógrafos e historiadores desde el siglo XVII (4).

En uno de los días en que el Venerable Varón estaba inmerso en meditar la Pasión se le apareció Cristo en el momento de su muerte y el santo, todavía bajo la impresión de la dolorosa imagen, la dibujó tal y como la guardaba en su memoria en "un trocito de papel». Al cabo de cierto tiempo lo entregó a la Madre Ana María de Jesús, religiosa del Convento e hija espiritual suya, a la que por el afecto que le guardaba le narró lo sucedido. Esta, a su vez, cedió el dibujo al Padre Juan de San José quien durante algún tiempo lo llevó consigo estimándolo y venerándolo como una reliquia. Más tarde, reclamado por la Madre Ana María de Jesús le fue devuelto y uella le guardó con gran veneración toda la vida, y al fin de ella le entregó como preciosa reliquia a la Religiosa Doña María de Pinel, que después

(3) El Padre Juan Bosco siguió muy de cerca estos trabajos aportando sus conocimientos bibliográficos sobre la vida de San Juan de la Cruz. Desde aquí quiero hacer constar mi agradecimiento por su cooperación.

(4) Entre otros, veáse Baruzi, J.: Saint Jean de la Croix et le probléme de l'experience mystique, París, 1924.

Orozco, E.: Mística y plástica. Comentarios a un dibujo de San Juan de la Cruz. Granada, 1939.

Vicenzo dell'Eucaristía, P. G.: "Il Cristo crocifisso nella visioni de S. Giovanni della Croce» en Il Carmelo elle sue vissioni n. ${ }^{\circ} 3-4,1963$, págs. 51-58. 
fue Priora del mismo Convento, la cual le tiene en particular relicario, con adornos y estima digna de tal prenda, por serlo de un tan gran Padre» (5).

En 1723 Benedicto XIII canonizó al Santo y consta que durante el proceso de Beatificación y Canonización se aceptaron los pormenores históricos expuestos, siendo de destacar que no se presentó al Tribunal el dibujo original sino una copia perdida o no localizada, de autor desconocido (6). Todo hace suponer que el relicario primitivo puede ser el mismo que en 1969, conteniendo el dibujo, ingresó en el Instituto Central de Conservación y Restauración.

Este relicario (lám. I, 1) es de plata y de labra muy sencilla. Su funcionalidad y ornato encajan plenamente en el estilo barroco de inicios del siglo XVII, siguiendo en su austeridad las disposiciones recomendadas por Felipe II sobre la no ostentación de los objetos religiosos.

El porta-reliquias, semejante a un ostensorio, está concebido para admirar las reliquias por ambas caras y no dispone de ningún sistema de cierre, salvo la propia presión de la caja y el contenido. Este, bien visible al exterior, estaba dedicado al espíritu y a la materia del santo, evocando su vinculación a la Santa de Avila, el anverso exhibía el dibujo de Cristo Crucificado y un fragmento de hueso atribuido al cuerpo del santo. En el reverso se contemplaba un fragmento de lino perteneciente al sudario y sobre él un papel verjurado manuscrito en caracteres de fines del siglo XVI-principios del XVII, con el verso siguiente: "Del tintero humedecido/de N. ${ }^{a}$ M. ${ }^{a}$ Theresa/esta letra ha merecido/el logro que aquí interessa".

Un conjunto de fragmentos de papel de "tina» con textos cuya grafía corresponde hacia las mismas fechas, se había preparado cuidadosamente adoptando su volumen al interior del estuche. De este modo se había preparado un almohadillado que aislaba las reliquias e impedía al mismo tiempo el desplazamiento del contenido.

El cariño y la meticulosidad puesto en la conservación y veneración de tan preciadas prendas se demuestra en el aspecto exterior. Esmaltes, pedrerías o adornos de otros años se habían sustituido por unos trocitos de seda de color rosa, verde y blanco adheridas al primer papel del relleno. Para enriquecer el campo y destacar las sedas se ocultó la superficie con un papel preparado con "bol" de oro en el que simulando cabujones se dejaban ver los trocitos de distintos colores y las ventanas abiertas para exhibir las reliquias (dibujo y hueso), enmarcado todo con un remate dentado muy primorosamente y adornos que imitaban los apéndices y volutas del propio relicario.

Esta debió ser la presentación primitiva. Más tarde, seguramente por la pérdida del dorado, se ocultó este papel con una fina lámina de pergamino recortado en filigranas y ajustado al relieve y a los espacios abiertos en el montaje primitivo. Sobre el pergamino se escribieron con tinta negra e iniciales rojas, letreros, alusi-

(5) De San José, Fray Jerónimo: Historia del Venerable Padre Fr. Juan de la Cruz, Madrid, 1641. Cap. Nono, pág. 187.

(6) Gran parte de los documentados presentados al proceso se guardan en la Biblioteca Nacional de Madrid. 
vos al contenido y al diálogo de Cristo con Juan de la Cruz que ahora ya es llamado Santo (siglo XVIII).

\section{Análisis material del dibujo: nuevos elementos}

El desmontaje completo permitió comprobar que el dibujo (lám. II, 1 y fig. 1) realizado sobre "un trocito de papel" presentaba aparente forma elíptica (dimensiones de ejes 64 y $51 \mathrm{~mm}$.), y estaba pegado con cola animal (cola de carpintero) a un segundo papel. Usando el mismo adhesivo ambos papeles se unían a un tercer soporte de pergamino y éste, finalmente, a una tablita de pino de $3 \mathrm{~mm}$. de grosor. Este conjunto se adaptaba en su tamaño a la forma oval de la ventana.

Respecto a las alteraciones sufridas hay que señalar, aparte de la lógica suciedad y envejecimiento, la existencia de manchas causadas por el adhesivo, la rigidez motivada por su cristalización y el alabeamiento de la madera con repercusión nociva en el conjunto de los 4 soportes (incluido el dibujo). Además, la superficie externa del dibujo mostraba un alto grado de suciedad con manchas oscuras de tonalidad rojiza, incrementadas parcialmente por un tinte grisáceo. Aunque en el interior no se localizaron insectos vivos o muertos, tanto la madera como los distintos papeles presentaban claras huellas de su actividad. También eran evidentes los microorganismos extendidos parcialmente por la superficie del dibujo (lám. I, 3).

En el conjunto de análisis (aparte de confirmar que el papel corresponde al llamado "de tina» de fibras liberianas y la tinta al grupo denominado "metaloácidas») se comprobó la existencia de un elemento extraño, motor de largas investigaciones porque afectaba directamente a la integridad espiritual e histórica del dibujo.

El examen al microscopio demostraba que los trazos de tinta de algunas zonas se apoyaban sobre este elemento cuyas características distaban mucho de las de cualquier papel. Justamente estas zonas, más o menos difuminadas por las manchas causadas por el adhesivo y la presencia de hongos, coincidían con los trozos de coloración grisácea muy oscura.

Tras los pertinentes análisis se comprobó que se trataba de una capa de preparación de blanco de plomo (carbonato básico de plomo) que en presencia del sulfuro de hidrógeno presente en el ambiente se había precipitado hasta formar sulfuro de plomo, característico por su coloración oscura, de ahí que las zonas ocupadas por este elemento presentaran esta tonalidad tan acusada.

Esta capa de preparación, puesta en escena con la intención de permanecer invisible, se introducía en la problemática, pasando a ser protagonista, de "media obra».

Con ayuda de microscopio y fotografías obtenidas por rayos ultravioletas (lám. II, 2) y transparencia (lám. II, 3) se delimitó casi en su totalidad la superficie ocupada por esta capa tan innecesaria como ajena a cualquier dibujo realizado a tinta. Los resultados llevaron a la conclusión de que la preparación se apoyaba directamente sobre la superficie del soporte que ocupa el área no cubierta con el resto del trocito de papel sobre el que originariamente trazó su dibujo San Juan de la Cruz. 


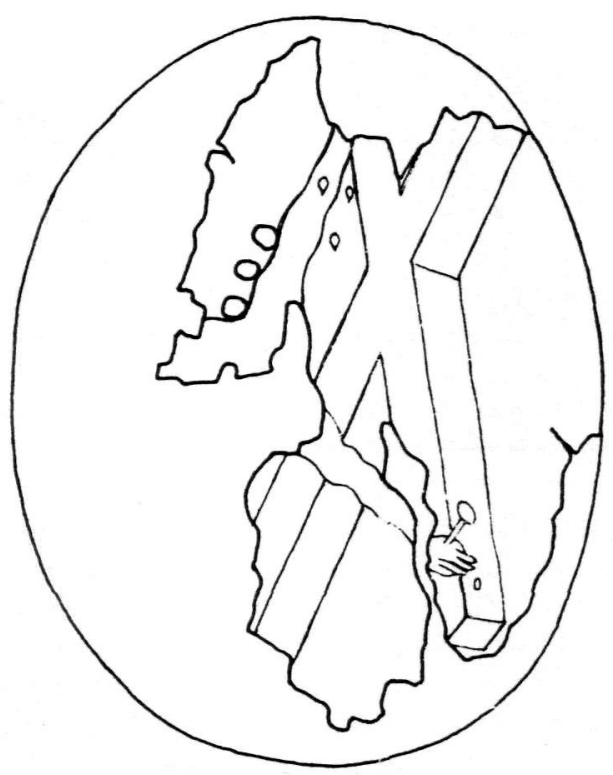

FIG. 1.-Posición de la Cruz en el relicario.

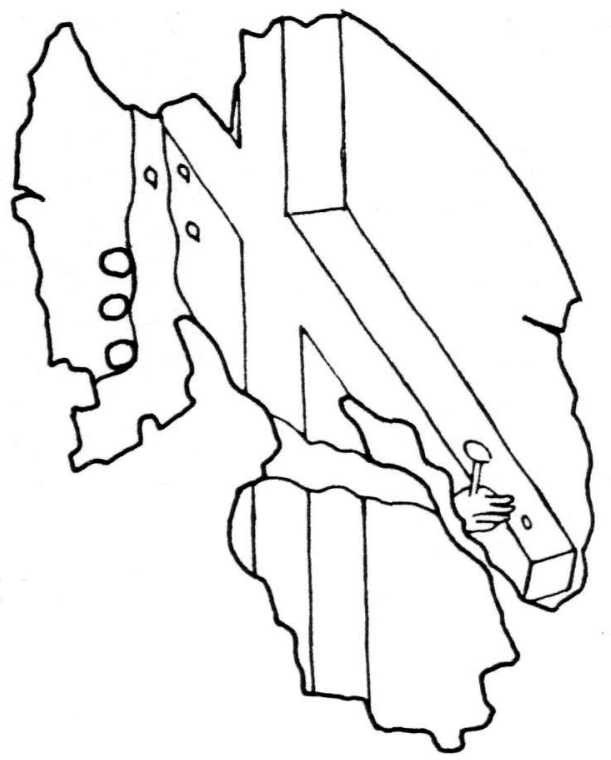

FIG. 2.-Posición teórica de la Cruz según el verjurado del papel original. 
Simultáneamente se logró delimitar este fragmento del papel, el genuino, de contorno irregular y muy exiguo. Ante la continuidad del dibujo sobre ambas materias - papel y capa de blanco de plomo- era obvio que la figura se había reconstruido y el estado actual era consecuencia de una doble fase: 1) Trazos del dibujo original sobre papel. 2) Trazos sobre la capa de preparación complementando el dibujo.

Llegados a este punto, de la recapitulación de los datos se desprende:

a) El papel utilizado por el Padre Juan de la Cruz para dibujar a Cristo, por pequeño que fuera, dispondría de la dimensión suficiente como para trazar la figura completa.

b) Por razones desconocidas este «trocito de papel» quedó reducido a un irregular fragmento en el que restaba solamente una reducida parte del dibujo realizado por San Juan.

Estas reflexiones llevan a pensar que al introducir el dibujo en el relicario su estado de conservación era tan pésimo que hubo necesidad de completarlo, recomponiéndolo adecuadamente. Los años que median entre la realización del dibujo y su colocación en el relicario, quizás más de medio siglo, son tiempo suficiente para que por uso indebido o exceso de celo (cosido a las ropas, prendido con alfileres, plegado...) o por cualquier otro accidente, el soporte perdiera sus dimensiones originales hasta reducir el dibujo a un $30 \%$ aproximadamente de los trazos primitivos. Para salvar la estética y la figura se reforzó pegándolo sobre otro papel de carácterísticas similares, adaptado al ventanal de exhibición y a las exigencias funcionales del relicario. Pero esta superposición del papel genuino sobre el segundo soporte acusaría al desnivel causado por el espesor del primero, bastante grueso por naturaleza. Para camuflar esta irregularidad se optó por aplicar a la superficie vista del segundo soporte la capa de blanco de plomo que sirvió para enrasar el escalón existente.

Esta preparación exige una base de mayor consistencia que un simple papel y así se justifica, tal vez, la colocación, primero, del pergamino y la solución final de la madera como soporte más rígido (aquí conviene hacer un inciso para recordar que, si el soporte accidental de pergamino no se hubiera interpuesto entre el papel y la madera, el dibujo y el segundo papel, contaminados por la acidez, se hubieran dañado irreversiblemente).

Una vez aplicada la preparación, ciertamente hábil, se reconstruyó el dibujo. Sin embargo, la reconstrucción de líneas no se interrumpe donde empiezan los trazos auténticos, sino que obligada la persona por la diferencia de intensidad de las tintas se "redibujaron" o repasaron los rasgos originales que, ya débiles, permanecían visibles, consiguiendo así que todos los trazos del dibujo tuvieran el mismo color.

Insistí en localizar los trazos primitivos, pero tanto la aplicación de rayos ultravioleta como infrarrojos (lám. II, 2, 3) dieron resultados negativos y sólo en aisladas zonas se delataban débiles indicios de una tinta muy empalidecida.

Es curioso observar que en la reconstrucción del dibujo no se completó el brazo derecho de la cruz, quedando sin delimitar el grosor del madero. También la mano izquierda y el extremo izquierdo del travesaño debieron sufrir transformaciones. 

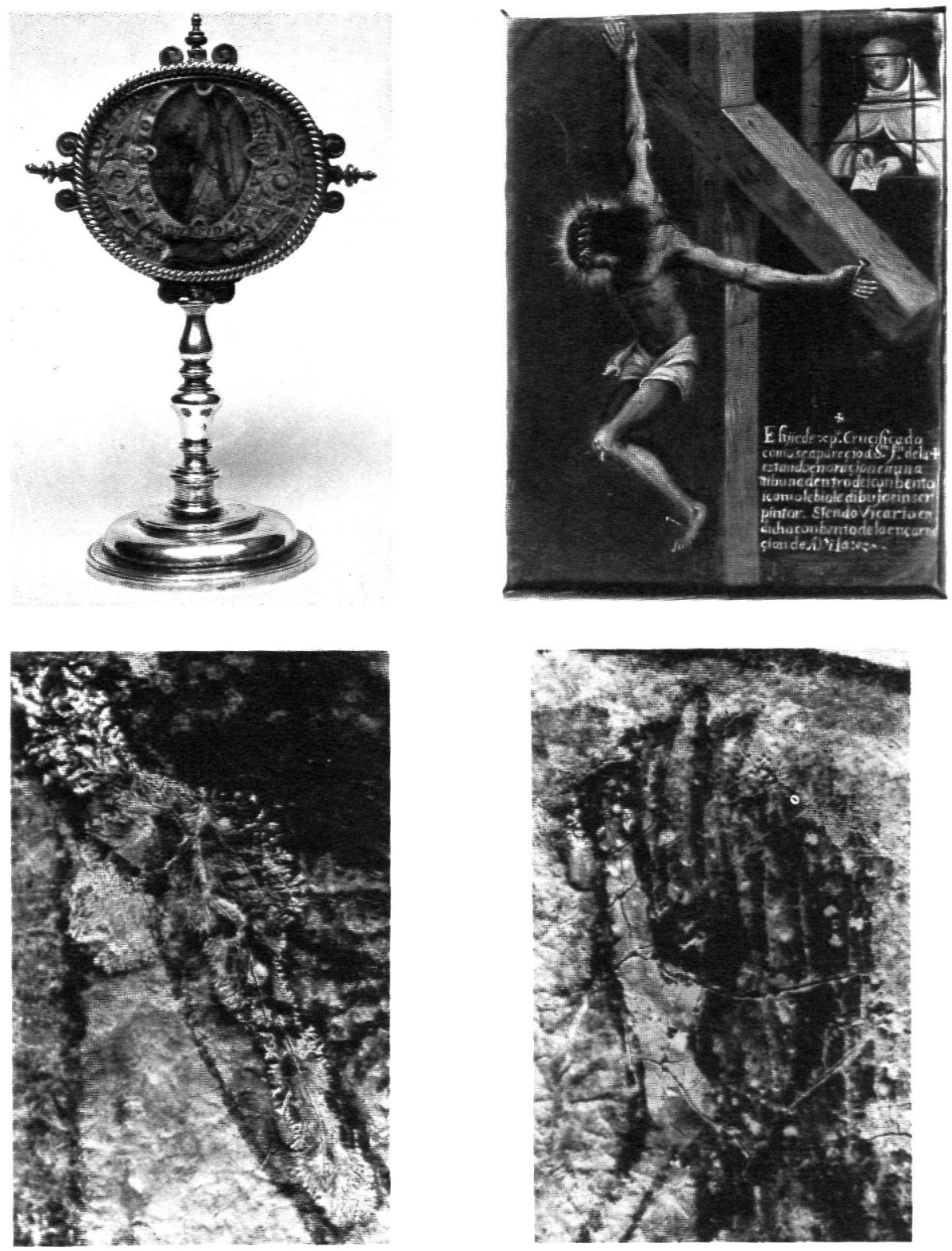

LÁm. I.-1. Relicario. Vista frontal. 2. Pintura anónima del s. XVII. Interpretación de la visión del Santo. 3. Detalle del desarrollo de microorganismos, a la altura del tórax. 4. Detalle del cuarteado de la capa de preparación. Mano derecha. 
Otro dato a indicar es que todo el óvalo está contorneado por una gruesa línea ejecutada tanto sobre la preparación como sobre el fragmento auténtico. El trazado, lejos de ser firme y regular, es desigual, fino o ancho, denotando una mano poco diestra. Tal vez se dibujara la elipse antes de recortar los soportes y después de acabado el dibujo; en cualquier caso parece coetánea a la reconstrucción aunque no se descarte una segunda mano.

\section{El dibujo}

Es innecesario aludir a los muchos comentarios suscitados por la maestría, perspectiva y escorzo de este dibujo. La insólita óptica sólo se puede concebir en el arte de un auténtico genio o por las circunstancias que precedieron a su trazado. La ponderación del Padre Jerónimo de San José, tan próximo en el tiempo, es bien elocuente y a su pluma debemos las consideraciones más acertadas sobre dónde estaría situado el siervo de Dios cuando se le apareció el Crucificado. "Tras consultar las reglas de la buena perspectiva» llega a la conclusión de que para hacer el escorzo el Padre Juan de la Cruz estaría situado por el lado izquierdo y no en el paralelo de los brazos «sino más fuera». A diferencia de la posición señalada en la pintura anónima de la lám. I, 2, el místico debía estar situado en alguna ventana o tribuna delantera, y más superior al lado del altar Mayor en medio del «qual se considera averle aparecido Cristo Crucificado buelto derechamente al pueblow (7).

Salvador Dalí, llevado por la admiración y entusiasmo de la dificultad técnica del dibujo y en especial por el escorzo, resultado de tan violenta perspectiva, interpreta personalmente la visión y consigue uno de los mejores cuadros, el conocido Cristo de San Juan de la Cruz hoy conservado en la "Art Gallery" de Glasgow.

No cabe duda que Dalí se dio cuenta del ángulo de visión concebido por San Juan, sin embargo, para acentuar todavía más la observación desde lo alto y la violencia de la perspectiva, centra el enfoque vertical y sitúa el punto de mira perpendicular al plano de la Cruz.

No todos los estudiosos y copistas han sido capaces de captar la realidad del ángulo y ni siquiera las reflexiones de Jerónimo de San José llevaron a Panneels, ilustrador de su obra, a hacer un buen grabado. El escaso tamaño del dibujo, casi una miniatura (brazo largo de la Cruz $5,7 \mathrm{~cm}$. y travesaño $4,7 \mathrm{~cm}$.) y la confusa visión se unen a la equivocada postura de la Cruz en el montaje del relicario. A esto habría que añadir que en copias e imitaciones los pies de Cristo aparecen traspasados indistintamente por uno o dos clavos.

¿Cómo fue en realidad el Cristo que dibujó San Juan?

Estamos lejos de contestar a esta pregunta. Tal y como se mostraba en el relicario se trata de una Cruz en diagonal con el punto más alto a la derecha (izquierda del espectador), formada por un grueso madero incompleto. Sobre el leño pende

(7) Ob. cit., nota 5. Ibídem. En realidad el santo debía estar delante de la Cruz y no detrás. 

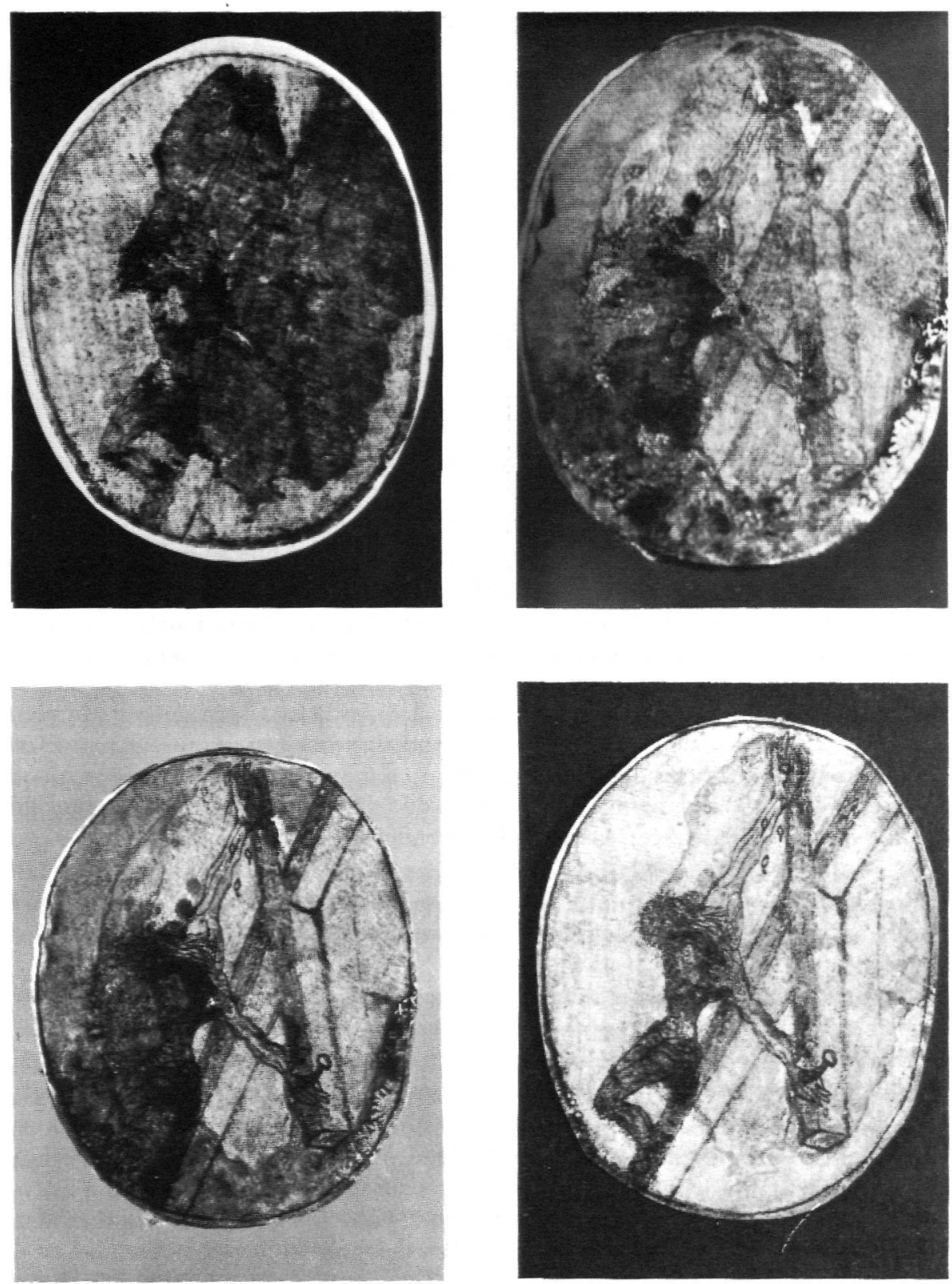

LÁM. II.-1. Antes de la restauración. 2. Fotografía con ultravioleta. 3. Fotografía por transparencia. 4. Después del tratamiento. 
la figura fuertemente escorzada en espalda, cuello y brazos, con los músculos bien marcados.

Tras eliminar microorganismos y otras alteraciones se comprobó que las manos eran muy deformes, bastante mal dibujadas, con dedos diferenciados pero muy toscos. La derecha lleva traspasada la palma con un clavo remachado del que sólo sobresale la gruesa cabeza (lám. I, 4). La izquierda, por el contrario, está atravesada por la parte superior con largo clavo de cabeza ovalada que, apenas hincado, atraviesa la mano debajo del dedo meñique. En el rostro no se identifican más rasgos que una confusa barbilla y la cabeza está ceñida por una corona representada a modo de cordón. El cabello, desmelenado y marcado por líneas sinuosas bien definidas, cae sobre la espalda hasta la altura de los hombros, confundiéndose con las líneas del cuello (borrosamente por delante de la cara se aprecia algún mechón).

Por efecto de la posición tan violenta, la cabeza se apoya sobre el pecho, rozándolo con el lateral derecho del rostro. En el cuerpo triangular sobresale un tórax ancho que muestra irregularmente la flacidez de las carnes insinuando las costillas (Es de destacar la falta de armonía entre la parte superior del costado derecho y la posición de la cabeza y del brazo izquierdo. Si se sigue la línea de musculatura es imposible establecer la unión con este lateral a no ser que se hubiera querido representar un cuerpo con el costado deforme y descoyuntado).

La cintura, exageradamente estrecha, se prolonga en las caderas y deja ver el ombligo. El paño de pureza, plegado y recogido a la izquierda, se ajusta a los muslos. Los miembros inferiores, menos musculosos que los brazos, se doblan en ángulo recto a la altura de las rodillas. La pierna izquierda está bien delimitada pero la derecha sólo se sigue en la parte interior, dando la sensación de que son paralelas.

Hoy advertimos borrosamente la sangre que mana del costado y de la mano izquierda, otras gotas debieron caer de la corona de espinas, llamando la atención la nitidez con que aparecen las gotas desprendidas de la mano derecha.

La zona de los pies es la más confusa. Por la posición de las piernas debían estar uno junto al otro, pero no se diferencian claramente y tampoco se constata la existencia de clavos (no pueden ser tomados como tales dos pequeñas manchas situadas junto al límite del madero).

Así, tal y como se sigue el dibujo, es imposible concretar la posición exacta de los pies y pronunciarse por el número de clavos (aunque si realmente estaban separados tendrían que ser dos). Un dato seguro es la carencia de supedáneo.

Suponiendo que el reconstructor repasara fielmente el dibujo sólamente queda incluido en el fragmento de papel original parte de la Cruz, brazos y espalda en su totalidad, parte de la mano y clavo izquierdo y parte de la cabeza sin incluir la corona de espinas. Es decir, están trazados sobre el blanco de plomo la mano derecha y su respectivo clavo, gran parte de la cabeza y el tronco y la totalidad de los miembros inferiores, así como los tramos del madero correspondientes a estas zonas.

Además, dentro del papel original algunas huellas confusas hacen sospechar que al redibujar los trazos primitivos el reconstructor tal vez se viera obligado a forzar 
algunas líneas para encajar su propio dibujo, dejando incompleto y sin concretar el travesaño derecho y la zona de los pies.

\section{Reflexiones artísticas}

Llegados a este punto me impuse confirmar la perspectiva exacta de la Cruz y rastrear si, efectivamente, tal y como se postula en los comentarios artísticos, San Juan se adelantó a renovar la iconografía dibujando en su siglo el primer Cristo con cuatro clavos, acorde a las revelaciones de Santa Brígida.

Respecto a las polémicas sobre el punto focal del artista y a la posición del dibujo en el relicario, todos los análisis confirman que la Cruz se había trazado con el madero largo completamente vertical. Al analizar la dirección del verjurado del papel los puntizones son perpendiculares a la verticalidad de la Cruz, y, en consecuencia, el larguero sigue la dirección de los corondeles (cosa que sería ilógica si se hubiese trazado el crucifijo en diagonal). Contrariamente la verjura del segundo soporte está colocada en el sentido de los ejes del óvalo, pero oblicuos respecto a la dirección de la Cruz (lám. II, 3).

Cuando se dibuja o escribe sobre un papel de tina la postura normal es colocar la hoja paralela al cuerpo siguiendo en el trazado la dirección de los puntizones (las líneas más juntas de la verjura).

Es completamente anómalo escribir trasversalmente sobre un papel de tina, máxime en una persona tan avezada como lo era San Juan. Para recabar más en esta lógica hice la prueba con diez personas que desconocían este trabajo. El resultado fue coincidente en colocar el papel en la posición supuesta, ratificando que si el primitivo papel muestra las líneas mayores de la Cruz siguiendo los corondeles el santo habría tomado el papel conforme a las normas más elementales del dibujo o la escritura.

Estas razones son un argumento más para puntualizar los juicios de Fray Jerónimo de San José: el madero era vertical y San Juan, sin lugar a dudas, se sitúa por encima y frente al Cristo, en un ángulo de unos $45^{\circ}$, en el lateral izquierdo de la Cruz (fig. 2).

Es por tanto errónea cualquier otra disposición, incluyendo la adoptada en el montaje tal vez justificado porque el dibujo estaba ya muy mutilado y debía adaptarse al fin concreto de relicario. Si se piensa en criterios religiosos es comprensible que la atención no recayera en la postura correcta sino en lograr que la cabeza y el lacerado cuerpo ocuparan el foco central de la contemplación.

La posición correcta se ratifica asimismo por la gravedad de brazos y cuerpo hacia el pie de la Cruz, con el Cristo apoyado en sólo cuatro puntos: clavos de ambas manos, nalgas y pies, mientras cabeza y tronco se adelantan por la lógica del desprendimiento.

Al modificar la posición de la cruz chocaría la caída de las gotas de sangre, por ello es comprensible, aunque resulte extraño en un dibujo de tan excelente calidad como debió ser el primitivo, que exista el error de interpretar las gotas de san- 
gre en sentido inverso al de la caída. La mano que las trazó era muy inexperta ¿coincide con la persona que marcó la línea de contorno?.

Respecto a la iconografía de los cuatro clavos hay que precisar que Pannels, llegado a España en 1638, lo reprodujo con la Cruz enhiesta y cuatro clavos, con los pies separados y sin otro apoyo. En otro grabado que ilustraba la visión se recurre a un crucifijo entre nubes con el mismo número de clavos pero con los pies cruzados. Semejante esquema se repite en un pintor anónimo del s. XVII mostrando los pies paralelos, pero dejando ver un solo clavo.

Todo lleva a pensar que los artistas conocían el dibujo directamente y estaban al tanto de las controvertidas polémicas sobre el número de clavos, suscitadas años después de trazado el dibujo por el Santo, pero en su tiempo ya no existían argumentos sobre cómo estaban clavados los pies.

Sabemos que en España el antecedente más directo de la reforma o innovación de las representaciones con cuatro clavos, tan vehemente defendida por el tratadista Pacheco y sus discípulos, se halla en el Cristo de El Escorial atribuido a Miguel Angel y traído desde Roma por Bautista Franconio en 1597. Es innegable que Pannels interpretó la visión recurriendo a este Cristo reproducido por Pacheco en una tabla de 1614. También Montañés coloca cuatro clavos en su Cristo de la Clemencia (1606), e igualmente aparece este número en algunos cuadros de Zurbarán, a partir de 1630, en el bien conocido Velázquez (1635) o en otros de Alonso Cano, Ribera...

En «El arte de la pintura» escrito en 1638, Pacheco (8) dedica el capítulo IX del libro primero a "Los nobles y santos que exercitaron la pintura y de algunos efectos maravillosos...". En él se hace referencia a San Juan de la Miseria (9) pero no a nuestro santo. Tampoco se cita a San Juan en el capítulo XV (en favor de la pintura de los cuatro clavos...) o en otras páginas en donde se recogen las cartas recabadas desde 1619 a 1629 sobre "el sentimiento y aprobación de los hombres doctos y prestigiosos en favor de la existencia de cuatro clavos" (10).

Los debates y la ignorancia sobre el original del Santo influyeron quizás en el reconstructor hasta el punto de no clarificar los clavos de los pies y optar por dejar la zona inferior bastante inconcreta.

Si estas reflexiones son correctas es evidente que la reconstrucción "restauradora» fue hecha dentro del ambiente que postula la renovación iconográfica. El trabajo fue ejecutado, verosímilmente, por una persona instruida en la técnica de pintura (la preparación de blanco de plomo es propia de la pintura sobre tabla o lienzo) y no puede descartarse la intrusión de otra segunda mano, con más voluntad que pericia. El proceso acaeció, según estas deducciones en las primeras décadas del siglo XVII con anterioridad a copias y réplicas.

(8) Pacheco, F.: Arte de la pintura, Edición del manuscrito original preparada y comentada por F. J. Sánchez Cantón, Inst. Valencia de D. Juan, Madrid, 1956, T. I, pág. 167-199.

(9) Fraile de origen italiano aficionado a la pintura que coincidió con Fray Juan de la Cruz en uno de los conventos. Es por tanto coetáneo a las circunstancias que nos ocupan. A él se atribuye un retrato de Santa Teresa.

(10) Ob. cit. nota 8, tomo II, págs. 362-433. 
En resumen, el dibujo atribuido a San Juan de la Cruz por circunstancias adversas sufrió tales pérdidas y alteraciones que tuvo que ser reconstruido en buena parte. A nuestros ojos el hecho aparenta un fraude, sin embargo gracias a aquella medida este dibujo ha llegado hasta la actualidad honrado y testimoniando las dotes artísticas del santo y conmoviendo a doctos y profanos.

Tras el tratamiento (lám. II, 4), centrado en la erradicación de los daños y adopción de medidas ante previsibles causas de alteración, se ha renovado el montaje. En nuevo estuche se ha instalado únicamente el dibujo, respetando el óvalo y la reconstrucción, consustancial ya a la integridad actual de la obra. El resto del contenido sigue en el relicario antiguo, todo ello conservado por las Madres Carmelitas en Avila para que futuros investigadores, si juzgan oportuno, insistan todavía más en los problemas planteados al tratar de inquirir la historia real de tan sorprendente testimonio. 
EDITA:

SERVICIO DE PUBLICACIONES DE LA

UNIVERSIDAD AUTONOMA DE MADRID 
En resumen, el dibujo atribuido a San Juan de la Cruz por circunstancias adversas sufrió tales pérdidas y alteraciones que tuvo que ser reconstruido en buena parte. A nuestros ojos el hecho aparenta un fraude, sin embargo gracias a aquella medida este dibujo ha llegado hasta la actualidad honrado y testimoniando las dotes artísticas del santo y conmoviendo a doctos y profanos.

Tras el tratamiento (lám. II, 4), centrado en la erradicación de los daños y adopción de medidas ante previsibles causas de alteración, se ha renovado el montaje. En nuevo estuche se ha instalado únicamente el dibujo, respetando el óvalo y la reconstrucción, consustancial ya a la integridad actual de la obra. El resto del contenido sigue en el relicario antiguo, todo ello conservado por las Madres Carmelitas en Avila para que futuros investigadores, si juzgan oportuno, insistan todavía más en los problemas planteados al tratar de inquirir la historia real de tan sorprendente testimonio. 